Revista Brasileira de Agricultura Irrigada v.14, nº.2, p. 3931 - 3940, 2020

ISSN 1982-7679 (On-line)

Fortaleza, CE, INOVAGRI - http://www.inovagri.org.br

DOI: $10.7127 /$ rbai.v14n101106

Protocolo 1106.20 - 28/10/2019

Aprovado em 05/06/2020

\title{
IRRIGAÇÃO COM DÉFICIT REGULADO EM DIFERENTES FASES DE CULTIVO DE BANANEIRA 'BRS PRINCESA'
}

Eugênio Ferreira Coelho ${ }^{1}$, Marcelo Rocha dos Santos ${ }^{2}$, Ruan Oliveira da Rocha Cruz ${ }^{3}$, Lenilson Weisner Ferreira Lima ${ }^{4}$, Damiana Lima Barros ${ }^{4}$

\begin{abstract}
RESUMO
A bananeira, cultivar BRS Princesa tem apresentado tolerância a déficit hídrico, sendo de boa aceitação no mercado. A constante instabilidade do regime pluviométrico em todas as regiões do Brasil indica a necessidade de uso mais eficiente de água na agricultura. Objetivou-se com este trabalho, avaliar características de crescimento e de produção da bananeira 'BRS Princesa' sob irrigação com déficit controlado. $\mathrm{O}$ delineamento experimental foi o inteiramente casualizado com sete tratamentos e três repetições. O ciclo da cultura foi dividido nas seguintes fases: fase I, do primeiro ao quinto mês; fase II do quinto ao sétimo mês e a fase III, do sétimo ao décimo segundo mês. Os tratamentos consistiram nas aplicações de $60 \%$ e $30 \%$ da evapotranspiração da cultura em cada fase do primeiro ciclo. A irrigação com déficit hídrico controlado não ocasionou alterações na altura de plantas, diâmetro do pseudocaule, número de folhas e área foliar da bananeira. Os valores médios de redução da produtividade foram maiores para aplicação do déficit hídrico na fase de floração, seguido da fase de crescimento de frutos e pela fase de crescimento vegetativo. Na fase vegetativa, a aplicação de $60 \%$ da lâmina total aplicada no ciclo não influenciou a produtividade.
\end{abstract}

Palavras-chave: Musa spp, déficit hídrico, manejo da irrigação.

\section{REGULATED DEFICIT IRRIGATION IN DIFFERENT GROWTH PHASES OF BANANA 'BRS PRINCESA'}

\begin{abstract}
${ }^{1}$ Ph.D. em Engenharia de Irrigação, Embrapa Mandioca e Fruticultura, Rua Embrapa SN, Bairro Chapadinha,CP 007, CEP: 44.380-000, Cruz das Almas, BA, Brasil. E-mail: eugenio.coelho@embrapa.br

${ }^{2}$ Prof. Doutor, Setor de Agricultura, Instituto Federal Baiano/Campus Guanambi, Zona Rural, Distrito de Ceraima, CP 009, CEP: 46.430-000, Guanambi, BA, Brasil. E-mail: marcelo.rocha@ifbaiano.edu.br

${ }^{3}$ Estudante de Agronomia, Universidade Federal do Recôncavo da Bahia/Campus Cruz das Almas, CEP: 44.380-000, Cruz das Almas, BA, Brasil. E-mail: ruan.oliveira.rocha@gmail.com

${ }^{4}$ Estudante de Doutorado em Engenharia Agrícola, Universidade Federal do Recôncavo da Bahia/Campus Cruz das Almas, CEP: 44.380-000, Cruz das Almas, BA, Brasil. E-mails: lenilsonlimaagro@gmail.com; damibarrosl@yahoo.com.br
\end{abstract}


Banana crop 'BRS Princesa' shows tolerance to soil water deficit and is well accepted in market. Continuous instability of rains in all over the country indicates the need for a more efficient water use in agriculture. This work aimed to evaluate growth and yield characteristics of 'BRS Princesa' banana under regulated deficit irrigation. The experimental followed an entirely randomized design with seven treatments and three replicates. The crop cycle was divided in the following phases: phase I, from the first to the fifth month; phase II, from the fifth to the seventh month, and phase III, from the seventh to the $12^{\text {th }}$ month. Treatments consisted on applications of $60 \%$ and $30 \%$ of crop evapotranspiration in each phase of the first cycle. Regulated deficit irrigation did not affect banana plant height, pseudo stem diameter, leaf numbers and leaf area. Mean values of yield reduction were larger for irrigation deficit in flowering phase, followed by deficit on growth fruit phase and by vegetative growth phase. In the vegetative phase, the application of $60 \%$ of the total water depth delivered during the crop cycle did not influence yield.

Keywords: Musa spp, water deficit, irrigation management.

\section{INTRODUÇÃO}

Diante de cenários de incertezas climáticas futuras, aumento de demanda de água no setor agrícola e escassez de recursos hídricos, a realização de trabalhos que possibilitam a disponibilidade de informação precisa para o produtor irrigante aumentar a eficiência de uso da água, é de fundamental importância para a sustentabilidade produtiva e ambiental.

$\mathrm{O}$ aumento da eficiência de uso da água é obtido com a manutenção ou aumento da produtividade com redução lâmina de irrigação aplicada. Algumas das estratégias de irrigação que proporcionam manutenção da produtividade com redução da quantidade de água aplicada é a irrigação com déficit hídrico controlado (Regulated deficit irrigation - RDI) (CHAI et al., 2016) ou a irrigação lateralmente alternada, também conhecida como secamento parcial de raízes (Partial rootzone drying PRD) (GOTUR et al., 2018). Em condições de semiárido brasileiro, a irrigação com déficit tem sido objeto de estudo em várias culturas, em lima ácida (SAMPAIO et al., 2014; SANTOS et al., 2016), em mangueira (SANTOS et al., 2014; SRIKASETSARAKUL et al., 2015; SANTOS et al., 2016; COTRIM et al., 2017), em pimentão (ROCHA et al., 2018) e em bananeira (SANTOS et al., 2017).

A irrigação com déficit controlado é uma técnica que consiste na aplicação do déficit hídrico em fases que a cultura apresenta menor sensibilidade, assim, esta redução na quantidade de água utilizada não deverá causará redução na produtividade além do aceitável a que justifiquem a economia hídrica (CHAI et al., 2016). É necessário, para isso, o conhecimento dos estádios nos quais a deficiência de água poderá provocar perdas consideráveis de produtividade e qualidade de frutos. Na cultura da bananeira, estudos com uso da RDI ainda são escassos. Por outro lado, com PRD, Coelho et al. (2019) verificaram que as produtividades sob irrigação lateralmente alternada com frequência de 7,14 e 21 dias, com $50 \%$ da evapotranspiração da cultura, promove uma redução na produtividade no segundo ciclo, comparada à produtividade da bananeira sob irrigação plena, no entanto, no primeiro e segundo ciclo, a eficiência de uso da água é maior sob condição de déficit hídrico.

A bananeira é uma planta exigente em água, assim, a indicação do uso do déficit hídrico controlado requer a realização de estudos que possibilitem entender qual fase do ciclo poderá reduzir a quantidade de água aplicada para que a produtividade $\mathrm{e}$ a qualidade do fruto não apresentem redução significativa, bem como, sem afetar os padrões comercias. Adicionalmente, o uso de cultivares mais tolerantes ao déficit hídrico, como a 'BRS Princesa' é outro aspecto relevante.

Assim, objetivou-se com o presente trabalho avaliar características de crescimento e de produção da bananeira 'BRS Princesa' 


\section{IRRIGAÇÃO COM DÉFICIT REGULADO EM DIFERENTES FASES DE CULTIVO DE} BANANEIRA 'BRS PRINCESA'

sob irrigação com déficit controlado em diferentes fases de cultivo.

\section{MATERIAL E MÉTODOS}

O trabalho foi realizado em área experimental da Embrapa Mandioca e Fruticultura, no município de Cruz das Almas - BA, a 225 metros de altitude e coordenadas geográficas de $12^{\circ} 48^{\prime} \mathrm{S}$ e $39^{\circ} 06^{\prime} \mathrm{W}$. O clima da região é classificado como úmido a subúmido, com uma pluviosidade média anual de 1143 mm (D'ANGIOLELLA et al., 2000).

$\mathrm{O}$ experimento foi conduzido em lisímetros de percolação construídos de caixas de fibra com as seguintes dimensões: $1,30 \mathrm{~m}$ de diâmetro por 0,60 $\mathrm{m}$ de profundidade. Cada lisímetro foi preenchido de forma a manter peneira de $5 \mathrm{~mm}$ de forma a manter uniformidade da densidade do mesmo em 1,3

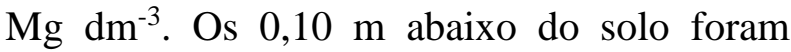
antes preenchidos, a partir do fundo da caixa com $0,07 \mathrm{~m}$ de brita número zero e $0,03 \mathrm{~m}$ de areia grossa. $\mathrm{O}$ solo foi amostrado até $0,40 \mathrm{~m}$ pela camada de apenas $0,10 \mathrm{~m}$ abaixo do mesmo até o material drenante. Vinte e um lisímetros foram instalados no campo e conectados a um sistema de drenagem onde toda a água drenada foi canalizada para uma estação de coleta. Em cada lisímetro, foi plantada uma muda de bananeira cultivar BRS Princesa, de forma que o espaçamento entre as plantas e entre as fileiras fosse de $2,0 \times 2,5 \mathrm{~m}$, respectivamente. $\mathrm{O}$ solo utilizado nos lisímetros foi classificado como Latossolo Amarelo Álico com classificação textural argilo-arenosa (EMBRAPA, 2018) (Tabela 1).

Tabela 1. Propriedades físicas do solo utilizado nos lisímetros, Cruz das Almas, BA, 2012

\begin{tabular}{ccc}
\hline Atributos & \multicolumn{2}{c}{ Profundidade $(\mathrm{m})$} \\
\cline { 2 - 3 } & $0,0-0,2$ & $0,2-0,4$ \\
\hline Areia $\left(\mathrm{g} \mathrm{kg}^{-1}\right)$ & 543 & 543 \\
Silte $\left(\mathrm{g} \mathrm{kg}^{-1}\right)$ & 101 & 101 \\
Argila $\left(\mathrm{g} \mathrm{kg}^{-1}\right)$ & 356 & 356 \\
Massa específica do solo $\left(\mathrm{g} \mathrm{cm}^{-3}\right)$ & 1,39 & 1,45 \\
Teor de água retido a $-10 \mathrm{kPa}\left(\mathrm{cm}^{3} \mathrm{~cm}^{-3}\right)$ & 0,229 & 0,258 \\
Teor de água retido a $-1500 \mathrm{kPa}\left(\mathrm{cm}^{3} \mathrm{~cm}^{-3}\right)$ & 0,160 & 0,192 \\
\hline
\end{tabular}

O delineamento experimental adotado foi $o$ inteiramente casualizado com sete tratamentos e três repetições. O ciclo da bananeira foi dividido nas seguintes fases de cultivo: Fase I, do plantio aos cinco meses após o plantio, considerada como de crescimento vegetativo; Fase II, dos cinco aos sete meses de cultivo, considerada como de floração e Fase III, dos sete aos doze meses de cultivo, onde ocorre predominância de crescimento dos frutos à colheita.

Os tratamentos foram diferenciados com a redução das lâminas de irrigação em uma das fases, aplicados da seguinte forma: RDI60I, $60 \%$ da ETc na fase I e $100 \%$ da ETc nas fases II e III; RDI30I, 30\% da ETc na fase I e 100\% da ETc nas fases II e III; RDI60II, $100 \%$ da ETc nas fases I e III e 60\% da ETc na fase II; RDI30II, $100 \%$ da ETc nas fases I e III e 30\% da ETc na fase II; RDI60III, $100 \%$ da ETc nas fases I e II e $60 \%$ da ETc na fase III; RDI30III, $100 \%$ da ETc nas fases I e II e 30\% da ETc na fase III, e irrigação plena - IP (100\% da ETc) em todas as três fases.

O momento da irrigação foi detectado pelas leituras de umidade em cada lisímetro, com uso de reflectometria no domínio do tempo (TDR), com base na umidade correspondente a capacidade de campo (Tabela 1). A irrigação foi com base na evapotranspiração da cultura, obtida em função da evapotranspiração de referência (ETo) e do coeficiente da cultura (Kc). A ETo foi determinada conforme modelo de Penmam-Monteith modificado, padrão FAO 56 (ALLEN et al., 1998), com dados dos elementos do clima obtidos de uma estação meteorológica automática localizada próximo do experimento e o Kc variou de 0,40 a 0,90 conforme Coelho et al. (2018). A aplicação do 
volume de água conforme demanda da cultura e conforme cada tratamento de déficit foi realizado com um regador e, quando havia possibilidade de ocorrência de precipitação, era adicionado uma cobertura plástica nos lisímetros para não influenciar nas respostas dos tratamentos impostos. As condições de temperatura e precipitação são mostradas na
Figura 1. A aplicação de nutrientes foi feita conforme análise do solo com planejamento de aplicação de $230 \mathrm{~kg}$ de $\mathrm{N}, 80 \mathrm{~kg}$ de $\mathrm{P}_{2} \mathrm{O}_{5}$ e 800 $\mathrm{kg}$ de $\mathrm{K}_{2} \mathrm{O}$ durante o ciclo, sendo o fósforo aplicado no plantio juntamente com 10 litros de esterco de curral e o nitrogênio e potássio aplicado semanalmente conforme recomendações de Borges e Costa (2009).



Figura 1. Temperatura máxima (Tmax), Temperatura mínima (Tmin) e precipitação (P) ocorridas no período de condução do experimento. Cruz das Almas, BA, 2012. Fonte: Elaboração dos autores.

Para análise de crescimento, no início de floração, avaliou-se a altura da planta, o diâmetro do pseudocaule e o número de folhas. Essas determinações não foram realizadas entre o início da floração e a colheita, uma vez que, após o florescimento não há emissão nem crescimento de folhas, é uma fase caracterizada pela senescência acelerada das folhas, e pela operação de desfolha para retiradas de folhas secas, quebradas pelo vento (DONATO et al., 2006). $\mathrm{Na}$ colheita, avaliou-se o número de folhas vivas e a área foliar (AF), estimada a partir da leitura do comprimento, da largura da terceira folha (folha nova) e do número de folhas, conforme Alves et al. (2001), (Equação 1).

$$
\mathrm{AF}=0,5789 \times \mathrm{C} \times \mathrm{L} \times \mathrm{NF}
$$

Em que: $\mathrm{AF}=\mathrm{a}$ área foliar total, $\mathrm{m}^{2} ; \mathrm{C}=$ o comprimento da terceira folha, $\mathrm{m} ; \mathrm{L}=\mathrm{a}$ largura da terceira folha, $\mathrm{m} ; \mathrm{NF}=\mathrm{o}$ número de folhas. No momento da colheita, em média, três meses depois da emissão do cacho, determinou-se o número de pencas, número de frutos e pesagem das pencas e do cacho para determinação da produtividade de pencas e de cachos. Foram medidos o comprimento e o diâmetro do fruto central da segunda penca (GUIMARÃES et al., 2013) utilizando uma fita métrica e um paquímetro. Com finalidade de verificar o impacto da RDI na produtividade, calculou-se $\mathrm{o}$ rendimento relativo à irrigação, que representa a redução percentual na produtividade de um tratamento com déficit em relação a irrigação plena.

Os dados obtidos de altura da planta, diâmetro do pseudocaule, número de folhas, área foliar, diâmetro do fruto mediano, comprimento do fruto mediano, número de frutos, número de pencas, produtividade de pencas e de produtividade de cachos foram submetidos à análise de variância (Teste F) e comparados pelo teste de médias de Tukey a $5 \%$ de significância, utilizando-se do programa estatístico SISVAR 5.0 (FERREIRA, 2011). 


\section{RESULTADOS E DISCUSSÃO}

Não houve influência das condições de déficit hídrico nas variáveis altura da planta, diâmetro do pseudocaule, número de folhas e área foliar da bananeira 'BRS Princesa' no início da floração. Como essas determinações foram realizadas na fase I, o déficit aplicado não foi suficiente para ocasionar alterações no status hídrico da planta. As médias de altura da planta, diâmetro do pseudocaule, número de folhas vivas no início da floração número de folhas vivas e área foliar na colheita são apresentados na Figura 2.

A altura e o diâmetro do pseudocaule das plantas, independente da condição de aplicação de água foi de $2,29 \mathrm{~m}$ e $0,25 \mathrm{~m}$, respectivamente (Figura 2A, 2B). Para esta mesma cultivar, ao analisar o desempenho agronômico de genótipos de bananeira no Recôncavo da Bahia, Roque et al. (2014) encontraram altura e diâmetro do pseudocaule de $3,3 \mathrm{~m}$ e $0,205 \mathrm{~m}$, respectivamente, no entanto, essa menor altura das plantas encontradas no presente trabalho, pode estar relacionada a fatores ambientais, uma vez que na condição de irrigação plena a altura das plantas não foi superior a $2,5 \mathrm{~m}$.

O número de folhas na emissão floral (Figura 2C) e na colheita (Figura 2D) foi de 10,45 e de 6,10, folhas por planta, respectivamente. Como descrito por Donato et al. (2015), o número de folhas funcionais para algumas cultivares como 'Prata-Anã' e 'Grande Naine' seria de 12 para atender o requerimento de produtividades normais. encontraram 11,66 e 5,66 folhas na floração e na colheita, respectivamente, da bananeira 'BRS Princesa' no primeiro ciclo de produção, o que apresenta concordância com o presente trabalho. A área foliar na época da colheita (Figura 2E), como consequência do número de folhas e do tamanho das mesmas, apresentaram valores menores do que $5,0 \mathrm{~m}^{2}$, considerado baixo. A capacidade das folhas do dossel em uma plantação para interceptar luz e fixar carbono é medida pelo índice de área foliar, IAF, que pode variar de acordo com a localização, densidade de plantio e vários outros fatores, incluindo a estação, e varia de 2 a 5 (TURNER et al., 2007).

No presente trabalho, com área foliar média de $4,11 \mathrm{~m}^{2}$, no espaçamento de $2,0 \mathrm{~m} \mathrm{x}$ $2,5 \mathrm{~m}$, resultaria em IAF de 0,82 . No entanto, após o florescimento não há emissão nem crescimento de folhas, o período entre o florescimento e a colheita dos cachos é caracterizado pela senescência acelerada das folhas, e pela operação de desfolha para retiradas de folhas secas, quebradas pelo vento (DONATO et al., 2006), o que pode explicar a baixa área foliar. As variáveis de produção avaliadas foram influenciadas pelos tratamentos de irrigação com déficit.

Para o número de frutos e de pencas por cacho (Tabela 2), apenas a condição em que aplicou $60 \%$ na lâmina na fase de crescimento vegetativo (RDI60I) diferiu significativamente comparado à irrigação plena $(100 \%$ da ETc) em todas as fases, com menor média de número de pencas e de frutos por cacho.

As demais condições de déficit, embora tenham proporcionado menores valores absolutos das médias de número de pencas e de frutos por cacho, não ocasionaram deferiram da média do número de fruto comparado à irrigação plena (IP) (Tabela 2). 

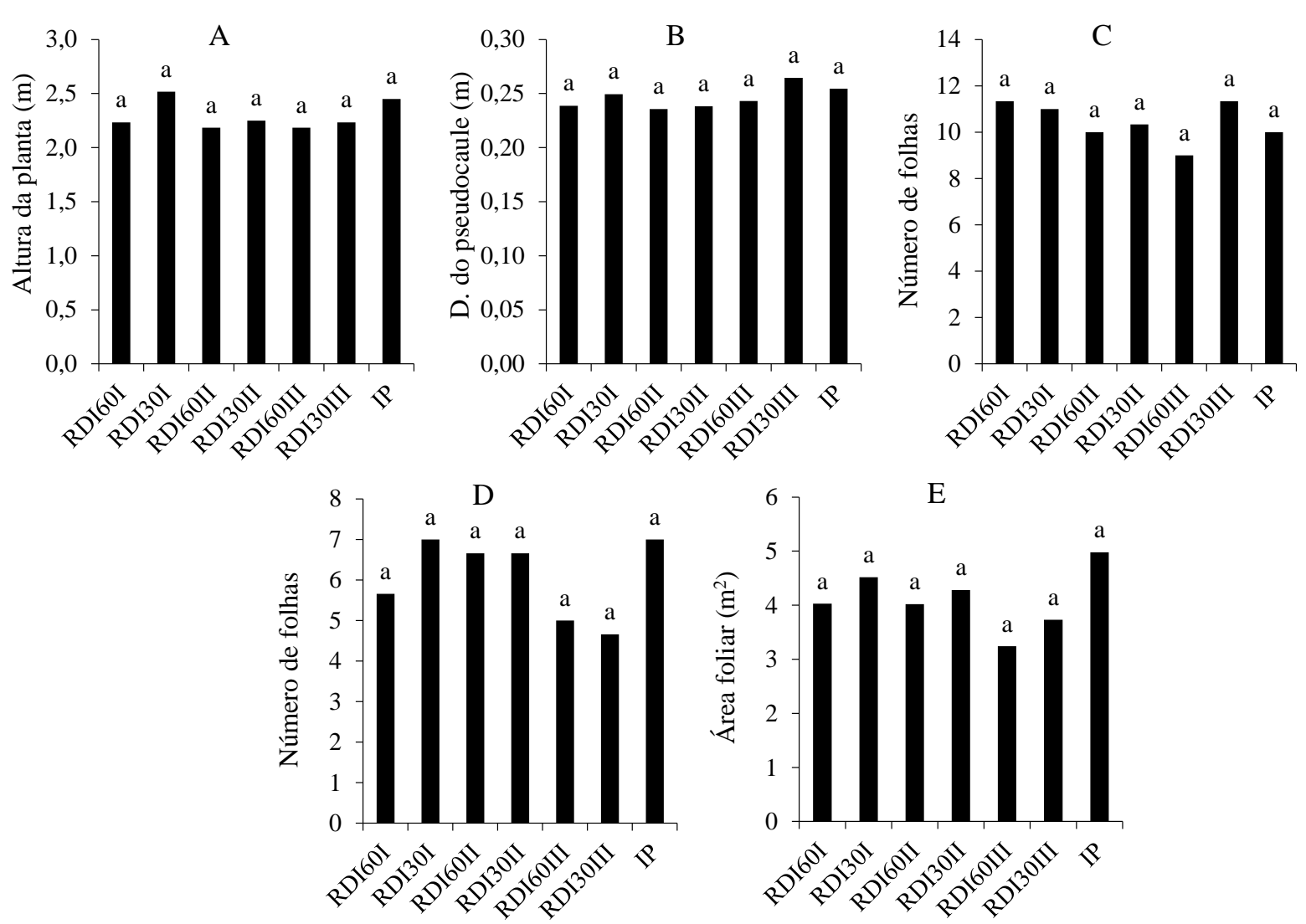

Figura 2. Altura da planta (A) com CV de 6,63\%, diâmetro do pseudocaule (B) com CV de 5,04\% e número de folhas (C) na emissão floral com CV de 9,59\%, número de folhas (D) com CV de 22,63\% e área foliar (E) com CV de 21,73\%, na colheita da bananeira 'BRS Princesa' sob diferentes reposições hídricas. Cruz das Almas, BA, 2012. RDI60I, $60 \%$ da ETc na fase I e 100\% da ETc nas fases II e III; RDI30I, 30\% da ETc na fase I e 100\% da ETc nas fases II e III; RDI60II, $100 \%$ da ETc nas fases I e III e 60\% da ETc na fase II; RDI30II, $100 \%$ da ETc nas fases I e III e 30\% da ETc na fase II; RDI60III, 100\% da ETc nas fases I e II e 60\% da ETc na fase III; RDI30III, $100 \%$ da ETc nas fases I e II e 30\% da ETc na fase III, e irrigação plena - IP (100\% da ETc) em todas as três fases Fonte: Elaboração dos autores.

A produtividade de pencas e de cachos da bananeira 'BRS Princesa', foi influenciada pelas condições aplicadas de déficit hídrico (Tabela 2). A produtividade de pencas sob RDI com 60\% da ETc na fase inicial (RDI60I) não apresentou redução quando comparada à irrigação plena (IP) por outro lado, as demais condições de déficit contribuíram para redução da produtividade de pencas. Mesmo com menor número de pencas sob RDI60I comparado à IP a produtividade de pencas e de cacho foi semelhante, provavelmente, menor número de pencas resultou e maior massa das pencas, resultado em maior produtividade, ilustrando assim a remobilização de fotoassimilados (SALISBURY; ROSS, 2012) para as pencas que ficaram em menor número.

A produtividade de cachos apresentou comportamento similar à produtividade de pencas, no entanto, pelo teste de Tukey a irrigação com déficit hídrico controlado com até $30 \%$ da ETc aplicado na fase inicial não causa redução na produtividade de cacho da bananeira 'BRS Princesa' comparada à irrigação plena (Tabela 2). Estes resultados são interessantes, pois, indicam que as fases de floração e de formação dos frutos são mais sensíveis ao déficit hídrico. 
Tabela 2. Número de pencas e de frutos por cacho, produtividade de pencas e produtividade de cachos, para a bananeira 'BRS Princesa' sob diferentes tratamentos. Cruz das Almas, BA, 2012

\begin{tabular}{ccccc}
\hline \multirow{2}{*}{ Tratamentos } & \multicolumn{2}{c}{ Número de } & \multicolumn{2}{c}{ Produtividade de } \\
\cline { 2 - 5 } & Frutos & Pencas & Pencas $\left(\mathrm{t} \mathrm{ha}^{-1}\right)$ & Cachos $\left(\mathrm{t} \mathrm{ha}^{-1}\right)$ \\
\hline RDI60I & $67,00 \mathrm{~b}$ & $6,0 \mathrm{~b}$ & $16,70 \mathrm{a}$ & $18,30 \mathrm{a}$ \\
RDI30I & $84,33 \mathrm{ab}$ & $7,0 \mathrm{ab}$ & $12,00 \mathrm{~b}$ & $13,40 \mathrm{bc}$ \\
RDI60II & $79,66 \mathrm{ab}$ & $7,0 \mathrm{ab}$ & $9,27 \mathrm{~b}$ & $10,07 \mathrm{c}$ \\
RDI30II & $91,33 \mathrm{ab}$ & $7,0 \mathrm{ab}$ & $9,70 \mathrm{~b}$ & $11,00 \mathrm{c}$ \\
RDI60III & $82,00 \mathrm{ab}$ & $7,0 \mathrm{ab}$ & $10,33 \mathrm{~b}$ & $11,30 \mathrm{c}$ \\
RDI30III & $92,00 \mathrm{ab}$ & $7,0 \mathrm{ab}$ & $10,33 \mathrm{~b}$ & $11,46 \mathrm{c}$ \\
IP & $95,50 \mathrm{a}$ & $8,0 \mathrm{a}$ & $16,70 \mathrm{a}$ & $18,10 \mathrm{ab}$ \\
\hline CV $(\%)$ & 10,20 & 8,64 & 22,77 & 22,95 \\
\hline
\end{tabular}

RDI60I, 60\% da ETc na fase I e 100\% da ETc nas fases II e III; RDI30I, 30\% da ETc na fase I e 100\% da ETc nas fases II e III; RDI60II, 100\% da ETc nas fases I e III e 60\% da ETc na fase II; RDI30II, 100\% da ETc nas fases I e III e 30\% da ETc na fase II; RDI60III, $100 \%$ da ETc nas fases I e II e 60\% da ETc na fase III; RDI30III, 100\% da ETc nas fases I e II e 30\% da ETc na fase III, e irrigação plena - IP (100\% da ETc) em todas as três fases. Médias seguidas da mesma letra nas colunas, não diferem pelo teste de Tukey a 5\% de significância.

$\mathrm{O}$ rendimento relativo à irrigação da bananeira 'BRS Princesa' sob as diferentes condições de déficit é apresentado na Figura 3, nota-se que a irrigação com déficit hídrico na fase de crescimento vegetativo é a que possibilita menor redução percentual na produtividade. $\mathrm{O}$ diâmetro de frutos da bananeira 'BRS Princesa' foi influenciado pelas condições de déficit hídrico no solo (Tabela 3). Apesar de não haver diferenças significativas no diâmetro do fruto da bananeira sob RDI comparado à irrigação plena (IP), a RDI com $30 \%$ da ETc na fase de floração ou de formações dos frutos contribui para menor diâmetro do fruto quando comparada com as médias de diâmetro do fruto sob RDI na fase vegetativa (Tabela 3), contribuindo assim, para as menores produtividades sob essas condições. Por outro lado, o comprimento do fruto não é afetado pela irrigação com déficit controlado, com média de $10,41 \mathrm{~cm}$.

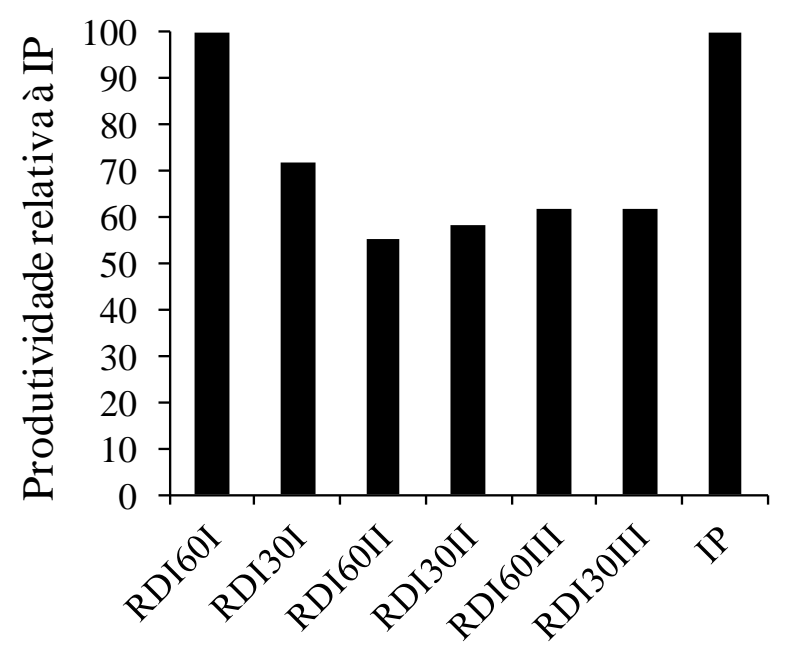

Figura 3. Relação percentual entre a produtividade da bananeira 'BRS Princesa' sob os diferentes tratamentos de irrigação com a irrigação plena (IP). Cruz das Almas, BA, 2012. Fonte: Elaboração dos autores. 
Tabela 3. Diâmetro e comprimento do fruto mediano da segunda penca da bananeira 'BRS Princesa' sob diferentes condições de irrigação com déficit hídrico controlado

\begin{tabular}{ccc}
\hline Estratégias & Diâmetro $(\mathrm{mm})$ & Comprimento $(\mathrm{cm})$ \\
\hline RDI60I & $33,50 \mathrm{a}$ & $11,00 \mathrm{a}$ \\
RDI30I & $28,33 \mathrm{ab}$ & $10,67 \mathrm{a}$ \\
RDI60II & $29,00 \mathrm{ab}$ & $10,57 \mathrm{a}$ \\
RDI30II & $26,00 \mathrm{~b}$ & $10,64 \mathrm{a}$ \\
RDI60III & $27,66 \mathrm{ab}$ & $10,67 \mathrm{a}$ \\
RDI30III & $24,66 \mathrm{~b}$ & $9,67 \mathrm{a}$ \\
IP & $30,50 \mathrm{ab}$ & $9,66 \mathrm{a}$ \\
\hline CV $(\%)$ & 8,95 & 9,97 \\
\hline
\end{tabular}

RDI60I, 60\% da ETc na fase I e 100\% da ETc nas fases II e III; RDI30I, 30\% da ETc na fase I e 100\% da ETc nas fases II e III; RDI60II, $100 \%$ da ETc nas fases I e III e $60 \%$ da ETc na fase II; RDI30II, $100 \%$ da ETc nas fases I e III e $30 \%$ da ETc na fase II; RDI60III, 100\% da ETc nas fases I e II e 60\% da ETc na fase III; RDI30III, 100\% da ETc nas fases I e II e $30 \%$ da ETc na fase III, e irrigação plena - IP (100\% da ETc) em todas as três fases. Médias seguidas da mesma letra nas colunas, não diferem pelo teste de Tukey a 5\% de significância.

Não há trabalho com objetivo semelhante para bananeira na literatura, entretanto os resultados são coerentes com os obtidos com outras culturas como mangueira (SANTOS et al., 2014; COTRIM et al., 2017) que também indicam a floração como a fase mais sensível ao déficit de água no solo para as plantas de mangueira. No entanto, diferentemente da mangueira, em que a fase de crescimento e maturação do fruto é menos sensível ao déficit hídrico, a bananeira apresenta maior sensibilidade ao déficit nestas fases, com isso, ressalta a necessidade de realização de trabalhos com a finalidade de indicação de uso da irrigação com déficit hídrico em determinada cultura em específico para indicação ao produtor.

\section{CONCLUSÕES}

As fases de floração e de crescimento do fruto da bananeira 'BRS Princesa' são sensíveis ao déficit hídrico.

A irrigação com déficit hídrico controlado com até $30 \%$ da ETc pode ser aplicada na fase de crescimento vegetativo na bananeira 'BRS Princesa'.

\section{REFERÊNCIAS BIBLIOGRÁFICAS}

ALLEN, R. G.; PEREIRA, L. S.; RAES, D.; SMITH, M. Crop evapotranspiration: guidelines for computing crop water requirements. Rome: United Nations Food and Agriculture Organization. 1998. 300p. Irrigation and Drainage Paper 56.

ALVES, E. J. Cultivo da bananeira tipo Terra. Cruz das Almas: Embrapa Mandioca e Fruticultura. 2001.176p.

BORGES, A. L.; COSTA, E. L. Banana. In: Ana Lúcia Borges; Eugênio Ferreira Coelho. (Org.). Feritirrigação em fruteiras tropicais. 2ed.Cruz das Almas, BA: Embrapa Mandioca e Fruticultura Tropical, 2009, v. 1, p. 97-105.

CHAI, Q.; GAN, Y.; ZHAO, C.; XU, H. L.; WASKOM, R. M.; NIU, Y.; SIDDIQUE, K. H. M. Regulated deficit irrigation for crop production under drought stress. A review. Agronomy for Sustainable Development, v. 36 , n. 3 , p. $1-21,2016$. DOI: http://dx.doi.org/10.1007/s13593-015-0338-6

COELHO, E. F.; SANTOS, M. R.; DONATO, S. L. R.; OLIVEIRA, P. M.; CASTRICINE, A. Soil-water-plant relationship and banana yield under partial root-zone drying irrigation. Scientia Agricola, v. 76, p. 362-367, 2019. DOI: http://dx.doi.org/10.1590/1678-992x2017-0258

COELHO, E. F.; SANTOS, M. R.; DONATO, S. L. R.; OLIVEIRA, P. M. Irrigação da bananeira cultivar BRS Princesa. Cruz das Almas, BA. Embrapa 
Mandioca e Fruticultura, 2018. 13 p. (Embrapa Circular Técnica, 126).

COTRIM, C. E.; COELHO, E. F.; SILVA, J. A.; SANTOS, M. R. Irrigação com déficit controlado e produtividade de mangueira 'Tommy Atkins' sob gotejamento. Revista Brasileira de Agricultura Irrigada, v. 11, p. 2229-2238, $2017 . \quad$ DOI: http://dx.doi.org/10.7127/rbai.v11n800728

D'ANGIOLELLA, G. L. B.; CASTRO NETO, M. T. DE; COELHO, E. F. Tendências climáticas para os tabuleiros costeiros da região de Cruz das Almas, Bahia. Revista Bahia Agrícola, v. 4, p. 14-16, 2000. Disponível em: <http://www.seagri.ba.gov.br/content/revistabahia-agr\%C3\% ADcola-v4-n1-nov-2000-issn1414-2368>. Acesso: 25 set. 2019.

DONATO, S. L. R.; ARANTES, A. M.; MARQUES, P. R. R.; RODRIGUES, M. G. V. Considerações ecofisiológicas e estratégias de manejo da bananeira. Informe Agropecuário, v. 36, p. 13-26, 2015.

DONATO, S. L. R.; SILVA, S. O.; LUCCA FILHO, O. A.; LIMA, M. B.; DOMINGUES, H.; ALVES, J. S. Comportamento de variedades e híbridos de bananeira (Musa spp.), em dois ciclos de produção no sudoeste da Bahia. Revista Brasileira de Fruticultura, v. 28, p. 139-144, 2006. DOI: http://dx.doi.org/10.1590/S0100-

29452006000100039

EMPRESA BRASILEIRA DE PESQUISA AGROPECUÁRIA - EMBRAPA. Centro Nacional de Pesquisa do Solo. Sistema Brasileiro de Classificação de Solos. 5.ed., rev. e ampl. - Brasília, DF: Embrapa, 2018. $356 \mathrm{p}$.

FERREIRA, D. F. Sisvar: a computer statistical analysis system. Ciência e Agrotecnologia, v. 35, n.6, p. 1039-1042, 2011. DOI: https://doi.org/10.1590/S141370542011000600001
GOTUR, M.; SHARMA, D. K.; JOSHI, C. J.; RAJAN, R. Partial root-zone drying technique in fruit crops: A review paper. International Journal of Chemical Studies, v.6, n.2, p.900903, 2018.

GUIMARÃES, B. V. C.; DONATO, S. L. R.; MAIA, V. M.; ASPIAZÚ, I.; RODRIGUES, M. G. V.; MARQUES, P. R. R. Simple and multiple linear regressions for harvest prediction of Prata type bananas. African Journal of Agricultural Research, v.8, n.48, p.6300-6308, 2013. DOI: http://dx.doi.org/10.5897/AJAR2013.7544

ROCHA, P. A.; SANTOS, M. R.; DONATO, S. L. R.; BRITO, C. F. B.; AVILA, J. S. Bell pepper cultivation under different irrigation strategies in soil with and without mulching. Horticultura Brasileira, v. 36, p. 453-460, 2018. DOI: http://dx.doi.org/10.1590/s0102053620180405

ROQUE, R. L.; AMORIM, T. B.; FERREIRA, C. F.; LEDO, C. A. S.; AMORIM, E. P. Desempenho agronômico de genótipos de bananeira no recôncavo da Bahia. Revista Brasileira de Fruticultura, v.36, n.3, p.598-609, 2014. DOI: https://doi.org/10.1590/01002945-361/13

SALISBURY, F. B.; ROSS, C. W. Fisiologia das plantas. 4ed. Tradução: SANTAROSA, P.L. São Paulo: Cencage Learning, 2012, $774 \mathrm{p}$.

SAMPAIO, A. H. R.; COELHO FILHO, M. A.; COELHO, E. F.; DANIEL, R. Indicadores fisiológicos da lima ácida 'Tahiti' submetida à irrigação deficitária com secamento parcial de raiz. Irriga, v. 19, p. 292-301, 2014. DOI: https://doi.org/10.15809/irriga.2014v19n2p29 2

SANTOS, M. R.; DONATO, S. L. R.; ARANTES, A. M.; COELHO, E. F.; OLIVEIRA, P. M. Gas exchange in 'BRS Princesa' banana (Musa spp.) under partial 
rootzone drying irrigation in the north of Minas Gerais, Brazil. Acta Agronomica, v. 66, p. 378, 2017. DOI: http://dx.doi.org/10.15446/acag.v66n3.55056

SANTOS, M. R.; DONATO, S. L. R.; COELHO, E. F.; ARANTES, A. M.; COELHO FILHO, M. A. Irrigação lateralmente alternada em lima ácida 'Tahiti' na região norte de minas gerais. Irriga, v. 1, p. 71, 2016. DOI: https://doi.org/10.15809/irriga.2016v1n01p71-88

SANTOS, M. R.; MARTINEZ, M. A.; DONATO, S. L. R.; COELHO, E. F. Produtividade e fotossíntese da mangueira 'Tommy Atkins' sob déficit hídrico em região semiárida da Bahia. Revista Brasileira de Engenharia Agrícola e Ambiental, v. 18, p. 899-907, 2014. DOI: http://dx.doi.org/10.159- 0/1807-1929/agriambi.v18n09p899-907

SRIKASETSARAKUL， U.; SRINGARM, K.; SRUAMSIRI, P.; ONGPRASERT, S.; SPREER, W.; SCHULZE, K.; MÜLLER, J. Effects of partial rootzone drying irrigation on proline content and yield of mango in a commercial orchard. Acta Horticulturae, n.1066, p.85-94, 2015. DOI: http://dx.doi.org/10.17660/ActaHortic.2015.10 66.8

TURNER, D. W.; FORTESCUE, J. A.; THOMAS, D. S. Environmental physioloy of the bananas (Musa spp.). Brasilian Journal of Plant Physiology, v. 19, n. 4, p.463- 484, 2007. DOI: http://dx.doi.org/10.1590/S167704202007000400013 